Saudi Journal of Oral and Dental Research

Abbreviated Key Title: Saudi J Oral Dent Res

ISSN 2518-1300 (Print) |ISSN 2518-1297 (Online)

Scholars Middle East Publishers, Dubai, United Arab Emirates

Journal homepage: https://saudijournals.com/sjodr

\title{
"Effect of the Polishing Procedures on Surface Roughness and Color Stability of Nanohybrid Composites"
}

Dr. K. Srinivasan MDS*

Reader Department of Pedodontics and Preventive Dentistry CKS Theja Institute of Dental Science and Research, Tirupati, India

DOI: $\underline{10.36348 / \text { sjodr.2020.v05i02.007 }}$

| Received: 19.02.2020 | Accepted: 26.02.2020 | Published: 29.02.2020

*Corresponding author: Dr. K. Srinivasan

\section{Abstract}

Background: In modern-day Dentistry, a significant emphasis is over esthetics. Hence, it is crucial to understand the various agents capable of adversely affecting the esthetics of a restoration due to its staining capacity. Objective: The aim of this in vitro study was to evaluate the effect of surface polishing, oral beverages and food colorants on the surface roughness and color stability of Restorative Materials. Materials and Methods: 60 Disks of Nanohybrid resin composite of different manufacturers measuring $4 \mathrm{~mm}$ in diameter and $5 \mathrm{~mm}$ in thickness were fabricated using a custom made Teflon mold. Pre-polishing surface roughness (Ra1) of all the five samples was measured using a Surface Profilometer. Pre immersion Spectrophotometric value $(\Delta \mathrm{E} 1)$ recorded for the baseline color of the samples. Three groups were formed consisting of 20 samples in each group, ie. Group I: Control group; Group II; Group III. The samples divided into subgroups (A, B, C, D), which was immersed in the respective test solution for 10 min thrice a day for 15 days. Sub Group- A - lipstick; Sub Group -B-Indian Blueberries; Sub Group-C -Sugar Candy; Sub Group -D -Carbonated drinkFanta. Post immersion Profilometric value was recorded to evaluate roughness brought about by the solutions (Ra2), and Spectrophotometric amount was recorded to evaluate the color change in samples $(\Delta \mathrm{E} 2)$. Results were statistically analyzed using ANOVA. Results: Mean roughness $\left(\mathrm{Ra}_{2}-\mathrm{Ra}_{1}\right)$ values are recorded in Sof-Lex, followed by the Diamond polishing paste and Control group. There were records of a Comparison of surface roughness caused due to beverages and food colorant solutions. Conclusion: Color alteration materials are affected by type and storage time.

Keywords: Beverage type; Color alteration; Spectrophotometer; Storage time; Surface Profilometer.

Copyright @ 2020: This is an open-access article distributed under the terms of the Creative Commons Attribution license which permits unrestricted use, distribution, and reproduction in any medium for non-commercial use (NonCommercial, or CC-BY-NC) provided the original author and source are credited.

\section{INTRODUCTION}

Resins were introduced to Dentistry nearly half a century ago as an esthetic restorative material. The awareness of the patient to have a restoration that is not only esthetic and natural-looking but also to have a long life has made Dentistry more challenging [1].

Dental restoration is the restorative material used to restore the function, integrity, and morphology of missing tooth structure that happened mostly due to dental caries or trauma [1].

Many metals like Gold, Platinum, Aluminium, and Tin were tried in the past as restorative materials [2]. The Dental resin-based composite is the material of choice for direct anterior restorations [3].

A Composite is a material made up of two or more constituent materials with significantly different physical or chemical properties when combined produce a substance with characteristics different from the individual components [3].

A dental composite typically consists of a resin-based oligomer matrix, such as Bisphenol AGlycidyl Methacrylate (BISGMA), Urethane Dimethacrylate (UDMA) or semi-crystalline Polyceram (PEX) and inorganic filler such as Silicon dioxide (silica) [3].

The disadvantages of Composites are a need for more skillful, laborious techniques during placement, polymerization shrinkage leading to secondary caries, stain more frequently, the tendency to wear comfortably, degrade in high alcohol content in drinks, and relatively expensive [4].

When the inorganic filler particles in the composites are nano-sized $\left(0.1-100 \mathrm{~nm}, 1 \mathrm{~nm}=10^{-9} \mathrm{~m}\right)$, they are called nano Composites. Tiny filler particles have dimensions that are below the wavelength of 
visible light (0.4-0.8micro meter), and hence, they are unable to scatter or absorb visible light. Thus, nanofillers are usually invisible and render the advantage of optical property improvement $[5,6]$.

The study aimed to evaluate the efficacy of various finishing and polishing systems using different procedures on surface roughness of esthetic restorative materials and also to evaluate the effect of immediate or delayed finishing/polishing procedures on surface roughness of esthetic restorative materials.

A well-finished restoration with less adhesive properties contributes not only to better esthetics but also reduces the development of secondary caries and periodontal disease.

Thus, we must remain aware of the right polishing system and timing for each material to obtain optimum results.

\section{MATERIALS AND METHODOLOGY Objectives and scopes}

This study aimed to contribute to the methodology of predicting the mechanical behavior of a Composite structure under aging.

\section{The objectives include}

- To quantify the water ingression behavior in Composite as a function of thicknesses.

- To determine the Surface Roughness properties of the Composite at different polishing agents.

- To evaluate the effect of duration on the degree of staining in the esthetic restorative materials immersed in a food simulating solution.

The present research was a double-blind experimental, interventional epidemiological study, and an in vitro study conducted at the Department of Pedodontics and Preventive Dentistry at CKS Theja Institute of Dental Sciences and Research, Tirupati and Chadalawada Ramanamma Engineering College, Tirupati (Andhra Pradesh state)

\section{The scopes of the research cover}

1. Materials: Dental Restoratives

2. Specimens and stacking sequences

a) Elementary- Surface roughness tests.

b) Staining agents- Indian Blue Berry; Sugar Candy; Carbonated drink- Fanta and Lipstick

3. Testing parameters and variables

a) Aging conditions: distilled water at room temperature.

\section{Dental Restoratives}

In this experimental investigation, Nanohybrid Composite resins currently indicated for esthetic anterior and posterior restorations.
The materials evaluated in the present study and their compositions and manufacturer details shown in Table 1, 2; Flow Chart 1.

\section{INCLUSION CRITERIA}

a) Discs with proper dimensions.

b) Discs free from surface voids or bubbles.

\section{EXCLUSION CRITERIA}

a) Discs with errors in dimensions (diameter and thickness).

b) Rough texture.

c) Visible surface voids or bubbles.

\section{Sample Fabrication Method}

Before carrying out the experiment, a power analysis was performed to identify the sample size required to detect significant effects accurately.

The sample size for the study, determined by fixing the probability of type I error at $5 \%$ and that of type II error at $20 \%$. Thus, the power of the study was $80 \%$.

$$
n(\text { sample size })=\left(Z_{\alpha}+Z_{1-\beta}\right)^{\alpha 2} / \mathrm{d}
$$

Where,

- $n$-sample size

- $d$ - minimum expected difference between 2 groups $=4.82$

- $\mathrm{Z}_{\alpha}=1.96, \mathrm{Z}_{1-\beta}=0.842$ (for $80 \%$ power).

- $\quad \Sigma$ - Standard deviation $=2.82$.

- $(\sigma$ and $\mathrm{d}$ are taken from the parent article.)

Hence, $n=4.37 \approx 5$

Taking into consideration, the experimental errors that would occur during the study, the sample size was taken to be as 5 per group.

In the present study, the materials used in the study had a different composition and polymerization types. All contents are commonly used and commercially available. A total of 60 disks shaped specimens (based on pilot study) using TETRIC $\mathrm{N}$ CERAM were fabricated.

The specimens were condensed in a circumferential cylindrical Polytetrafluoroethylene (PTFE) [7] (Parshwa Polymer Industries, Mumbai Maharashtra) mold with $4 \mathrm{~mm}$ of internal diameter and $5 \mathrm{~mm}$ thickness [8]. It was positioned onto a $0.051 \mathrm{~mm}$ thick by transparent tape-Polyester Matrix Strip [8] (Samit Matrix, India) and glass microscope slide with a thickness of $1 \mathrm{~mm}[9]$ to prevent air trapping, to remove excess and create a smooth surface. 
A sample smaller than this dimension makes Spectrophotometric testing difficult, and a larger size carries no additional advantage in getting accurate results.

Enamel A2 shade was used to standardize the degree of polymerization and evaluating gloss surface using Glossometer (Swastik Scientific Instruments, Private Limited, Maharashtra, India).

A Glossmeter was used to measure gloss at a $60^{\circ}$ angle from normal to the surface. An Electronic Digital Vernier Caliper (Precision Scientific Instruments Corporation, India) checked the thickness and diameter of each test specimen [10].

Another $0.051 \mathrm{~mm}$ thick transparent Polyester film strip was applied on top of the PTFE matrix filled with the tested material.

An additional glass slide was placed over the previously positioned Polyester film strip under a static load of the approximate weight of $200 \mathrm{~g}$ for one min until it had a tight uniform contact with the Teflon mold.

A static load applied to extrude excess material to flow before curing, to avoid air entrapment and to obtain a smooth and flat surface on each specimen. This technique ensures equal pressure and creates a flat surface on all the samples which were fabricated [11].

The scalpel blade \#15 (Ribble International Ltd) removed the excess material [11]. The manufacturer instructed to test and manipulates the weight.

The specimen material was light (Woodpecker I-Led Light Cure) polymerized for 40 seconds with a wavelength of $430-480 \mathrm{~nm}$ through the polyester film strip. The output light intensity was continuously monitored with a Dental Radiometer [12] (Demetron, Kerr, Sybron Dental, Orange, CA, USA) to ensure a constant value of $1200 \mathrm{~mW} / \mathrm{cm}^{2}$

The specimens were compacted into molds in a single increment using gold-coated plastic filling instruments [13] and cured.

To normalize the distance between the device and the sample surface, the device head was placed vertically in contact with $1 \mathrm{~mm}$ thick glass slide. All the specimens were stored in distilled water at $37^{\circ} \mathrm{C}$ for 24 hours in an incubator (SGM Lab Solutions Pvt Ltd, NewDelhi, India) to ensure complete polymerization, leaching of any non-polymerized resins and establishing equilibrium in water uptake.
The Teflon rings inspected for smoothness individually. Defective rings replaced with rings of uniform smoothness and dimensions. The specimens did not undergo any mechanical preparation or abrasions [14].

\section{Water uptake $[15,16]$}

Resin matrix is the weakest part that water sorption, while the filler particles cannot absorb water into the bulk of the material but can absorb it onto the surface. Therefore, the water sorption is dependent on the amount of resin matrix content of the Composite. Besides, it dependents on the quality of the bond between the resin matrix and the filler.

Excessive water sorption can decline the longevity of resin Composite by expanding and plasticizing the resin component, hydrolyzing the saline, and micro-crack. These micro-cracks permit penetration that causes discoloration.

For water uptake measurement, 60 Specimens as disc form were dried in a vacuum oven at $70^{\circ} \mathrm{C}$ until a constant weight was attained. Specimens were dried and pre-weighed before immersion in beverages, food products, cosmetic material, and later at an interval of 15 days.

A Weighing Scale (Precision Scientific Instruments Corporation, India) with an accuracy of 0.1 $\mathrm{mg}$ measured the dry weight $(\mathrm{Md})$ and the weight during immersion $(\mathrm{Mw})$.

After removing the water measurement of the weight gain of the specimens took place. An Equation determined the percentage gain at time $t,\left(m_{t}\right)$ as a result of moisture absorption

$$
\text { Water uptake } \%=\left(\mathrm{m}_{\mathrm{wt}}-\mathrm{m}_{\mathrm{d}}\right) / \mathrm{m}_{\mathrm{d}} \times 100(\%)
$$

Where, $W_{d}$ and $W_{w}$ denote the initial weight of specimen before exposure to the water uptake and mass of the sample after exposure to water absorption, respectively

Where " $\mathrm{t}$ " is days of water immersion.

A digital thermometer measured the temperatures (Swastik Scientific Instruments, Private Limited, Maharashtra, India)

Sample grouping: [15-22]

The Nanohybrid Composite resins disks were then randomly divided into three groups, with 20 samples in each group. ( $\mathrm{n}=60$ each)

Before exposure to the staining agents, the Spectrophotometer recorded the baseline color measurement of all specimens. Subsequent color measurements were taken at the end of 15 days of immersion in the Staining agents. 
The 60 samples were then segregated randomly to constitute the three test groups - Group I (Control), Group II, and Group III (Experimental).

Group I: Control group: The samples were not subjected to any polishing procedures.

Group II: Sof-Lex group: (ESPE, St. Paul, MN, USA). Samples subjected to polishing using different grits of Sof-Lex disks.

Group III: Diamond polishing system group: (3M ESPE, St. Paul, MN, USA) Samples were subjected to a polishing system consisting of diamond particles.

For the color stability in different solutions, each group was divided into four subgroups of 5 specimens each according to the staining solutions used.

\section{Finishing and polishing of the restorative material:}

Carbide and diamond finishing burs, abrasive impregnated rigid points, impregnated rubber cups and points, Aluminium oxide coated abrasive discs, abrasive strips, and polishing pastes, commonly used for finishing and polishing tooth-colored restorative materials.

Each of these instruments or devices remove the oxygen inhibited layer of resin but leaves the surface of restorative materials with varying degrees of surface roughness. Thus it is crucial to understand which type of surface-finishing treatments would significantly affect the surface irregularities of different composite resin restorations.

In the present study samples of Group, 1- No mechanical preparation or abrasions of the specimens was performed for the control group.

In Group II, Finishing and polishing were carried out, with Aluminum oxide discs in a sequence of decreasing abrasiveness with rhythmic movements. The coarse and medium grit disks were used for ten strokes before proceeding to the next grit, following the manufacturer's instruction.

In Group III, the Finishing and polishing of specimens belonging to this group were carried out using a diamond polishing system with a particle size of $0.5 \mu \mathrm{m}$.

Polishing was carried out using a contra-angle handpiece (NSK -Nakanishi International) at a low speed of 18,000 revolutions per minute slow speed.

The polished specimens had their thickness measured with an Electronic Digital Vernier Caliper accurate to $0.1 \mathrm{~mm}$.
The superior and lateral surfaces of samples were polished using the polishing agents. Light to no pressure was applied during the procedure, and the disks were directed in one direction from left to right, back and forth movement was avoided.

Distilled water at 370c stored the polished specimens. The specimen surface was kept moist, discarded after a single-use. Each drive was used on the dampened surface for 15 seconds.

For four minutes, ultrasonic cleaning of the polished specimens took place in freshly prepared distilled water to remove the debris and keep the samples clean. Polishing procedures were kept to minimum time, 10 s for each step, to avoid micro-crack formation.

\section{Surface Roughness assessment}

Sophisticated instruments, such as non-contact Optical Interferometers and atomic Force Microscopes (AFM), are available to measure Roughness at a much higher resolution and over a larger area. These devices might prove useful in future in-depth analyses.

In the present study, all the specimens were subjected to Surface Roughness testing using a contact Profilometer (Gaging Industries, Las Vegas). It had a 5 $\mu \mathrm{m}$ radius diamond- tipped stylus that was attached to a pickup head. The stylus traversed the surface of the specimen at a constant speed of $0.5 \mathrm{~mm} / \mathrm{s}$ with a force of $4 \mathrm{mN}$ and automatic return.

Each specimen was traced in four parallel locations near the center across the finished and polished surface with an evaluation length of $4 \mathrm{~mm}$.

The average roughness value $(\mathrm{Ra}, \mu \mathrm{m})$ of an individual disc was taken as the mean of the $\mathrm{Ra}$ (average of peaks and valleys of a surface) values. The measured were obtained in five different positions (1.5 $\mathrm{mm}$ apart), each before and after immersion in the staining agents. The change in surface roughness was measured as follows:

$$
\mathrm{Ra}=\mathrm{Ra}_{2}-\mathrm{Ra}_{1}
$$

With the statistical analysis, we analyzed the obtained results. Data were presented as mean and standard deviation (SD) values.

By adjusting the pick-up head knob, we achieved the leveling of the parts of the apparatus. A calibration block was used periodically to check the performance of the device.

The area to be scanned Profilometrically was 1 $\mathrm{mm} \times 0.9 \mathrm{~mm}$. 
Measurement of the Pre polishing Surface Roughness $\left(\mathrm{Ra}_{1}\right)$, Post polishing Surface Roughness $\left(\mathbf{R a}_{2}\right)$

After the specimens were polished, baseline measurements were taken to record gloss and Surface Roughness.

Pre-polishing $\left(\mathrm{Ra}_{1}\right)$ and post-polishing Surface Roughness $\left(\mathrm{Ra}_{2}\right)$ of all the 60 samples each of the Nanohybrid Composite were measured using a Surface Profilometer.

The obtained value was recorded as the prepolishing Surface Roughness as Ra1 and post-polishing Surface Roughness as $\mathrm{Ra}_{2}$.

\section{Dietary colorant selection and preparation}

The dietary colorants used in this study were common beverages with natural and artificial colors that may cause staining of specimen surfaces.

The Dietary colorant was: Indian Blue Berry; Sugar Candy; Carbonated drink- Fanta and other products Lipstick procured from the local market.

The Fruits samples were cleaned manually to remove all foreign materials such as dust, dirt, immature fruits, and much more.

We prepared freshly squeezed and strained $100 \%$ Indian blueberry juice. The lids of the containers containing carbonated drink- Fanta were tightly closed to prevent the escape of carbonic gas.

We took special care while dispensing the soft drink. For maintaining an acceptable level of carbonic gas, we opened a new bottle for every 24-hours of immersion in the beverage, with the excellent drink remained in the container, which was discarded.

The specimen immersion protocol simulated an individual eating acidic food, sour fruits, and drinks. The samples were rinsed with distilled water and then were kept in artificial saliva at $37^{\circ} \mathrm{C}$ in an incubator (Scientech Instruments, New Delhi, India) to mimic human oral conditions until the point of immersion in the subsequent liquid. We repeated this procedure for 15 days, and each fluid was renewed every day to prevent contamination by yeast or bacteria.

A digital Thermometer measured the temperatures (Swastik Scientific Instruments Private Limited). During the experiment, the containers were covered to prevent evaporation of the solutions.

\section{Artificial saliva}

The artificial saliva was prepared in the laboratory using the formula suggested by Shannon. $1.21 \mathrm{~g} / \mathrm{l}$ - Potassium Chloride (KCl); 0.4 g/l- Sodium Chloride ( $\mathrm{NaCl}) ; 0.005 \mathrm{~g} / \mathrm{l}$ - Hydrated Sodium Sulfide
$\left(\mathrm{Na}_{2} \mathrm{~S} .9 \mathrm{H}_{2} \mathrm{O}\right) ; 1 \mathrm{~g} / \mathrm{l}$ - Urea $\left\{\mathrm{CO}\left(\mathrm{NH}_{2}\right)_{2}\right\} ; 0.78 \mathrm{~g} / 1$ Sodium Dihydrogen Phosphate Dihydrate $\left(\mathrm{NaH}_{2} \mathrm{PO}_{4} \cdot 2 \mathrm{H}_{2} \mathrm{O}\right)$ and $1000 \mathrm{ml}$ of Deionized water.

A $10 \mathrm{~N}$ Sodium Hydroxide was added to this mixture. The $\mathrm{pH}$ value was adjusted to $7.02 \pm 0.15$ by using Digital $\mathrm{pH}$ meter (M/s. Contech Instruments Limited, Navi Mumbai, India). Later this mixture was sterilized in the autoclave (Bionics scientific technologies Pvt Ltd.)

\section{pH determination}

The $\mathrm{pH}$ analyses of the staining solutions were measured at room temperature by a Digital $\mathrm{pH}$ meter. (M/s. Contech Instruments Limited, Navi Mumbai, India)

Probe and meter method was used to assess the $\mathrm{pH}$ by using two buffers ( $\mathrm{pH} 7$ and 10). First, the $\mathrm{pH}$ meter was calibrated with a measurement error of 0.01 using standard buffers at $\mathrm{pH} 9.25, \mathrm{pH} 7.02$, and $\mathrm{pH} 4$. Then, $2 \mathrm{ml}$ of the solution was poured into beakers, and the $\mathrm{pH}$ meter was placed in it. The $\mathrm{pH}$ of each sample was measured in triplicate, and the data's mean was recorded.

\section{Determination of Titrable Acidity (TA)}

Maguire method was used to determine TA. $0.1 \mathrm{M}$ Sodium hydroxide $(\mathrm{NaOH})$ droplets were added to the sample by abort to reach a $\mathrm{pH}$ of 5.5 in $\mathrm{pH}$ meter. Each sample was titrated three times with this method, and we recorded the average amount of Sodium hydroxide. The data obtained are calculated using the formula:

$$
\begin{aligned}
& \text { Where, } \\
& \mathrm{TA}=0.1 \times(\alpha / 2 \times 5 \mathrm{~mL})
\end{aligned}
$$

into 2.

Solutions with TA $<0.5$ are placed in the low- erosion group, TAs in the range of 0.5

2.5 in the moderate erosion group, and TAs $>2.5$ are placed in the high- erosion group.

In the present study, we used the $\mathrm{TA}<0.5$.

\section{Immersion of the composite disks in Oral beverages and food colorants and measurement of color change}

To mimic the daily consumption of a person, after $24 \mathrm{~h}$ of incubation, each sample was immersed in the respective test solution for $10 \mathrm{~min}$, thrice a day for 15 days.

30 specimens were used as control while other 60 examples subdivided into twelve subgroups $(n=5)$ : 
- Subgroup I, IV, VII, X-Samples immersed in lipstick; Indian Blue Berry solution (30 ml); Candy lollipop; carbonated drink and Artificial saliva (30 $\mathrm{ml}$ )for $10 \mathrm{~min}$, three times daily for 15 days at $37^{\circ} \mathrm{C}$.

- $\quad$ Subgroup II, V, VIII, XI-Samples were polished with Sof-lex for one min and then immersed in lipstick; Indian Blue Berry solution (30 ml); Candy lollipop; carbonated drink and Artificial saliva (30 $\mathrm{ml}$ )for $10 \mathrm{~min}$, three times daily for 15 days at $37^{\circ} \mathrm{C}$.

- $\quad$ Subgroup III, VI, IX, XII -Samples were polished with a Diamond polishing system for one min and then immersed in lipstick; Indian Blue Berry solution (30 ml); Candy lollipop; carbonated drink and Artificial saliva $(30 \mathrm{ml})$ for $10 \mathrm{~min}$, three times daily for 15 days at $37^{\circ} \mathrm{C}$.

For accurate calculations of a timeline, we maintained a detailed record of the time and date of measurements.

\section{Pre and post immersion Spectrophotometric value ( $\Delta E 1$ and $\Delta E 1)$ \\ Baseline color assessment}

Discoloration can be assessed visually and by using specified instruments as Spectrophotometer, an Easy shade that can eliminate individual errors in color assessment.

Each specimen was removed from the artificial saliva, rinsed with distilled water, dried, and with then blotted dry using a filter paper. (Whatman's Filter Paper) to avoid unnecessary reflection of light and recorded initial readings.

A spectrophotometer with an integrating sphere can operate at two different measuring geometries the specular component included (SCI) geometry, and the specular component excluded (SCE) geometry (Lee YK)

The color of all samples before immersion in the staining agents. Using a Reflection Spectrophotometer (PCB 6807 BYK Gardner, Geretsried, Germany) with CIE Lab technology the preimmersion Spectrophotometric value $(\Delta \mathrm{E} 1)$, post immersion in the beverages, food colorant, and cosmetic material were obtained

Subsequent color measurements were taken at the ends of days 15 of immersion in the Staining media to obtain the post immersion Spectrophotometric value $(\Delta \mathrm{E} 2)$.

Before each measurement, we calibrated the Spectrophotometer according to the manufacturer's instructions.

\section{Color Measurement}

The trained examiner measured a specimen's color by computer-controlled Spectrophotometer using a standard $\mathrm{L} * \mathrm{a} * \mathrm{~b} *$ color scale before and after the staining agent applications at various time intervals $(0$, 15 days). CIE Lab system is a three-dimensional colorimetric system.

The software used was Novascan color matching and analysis software. Color is measured according to the CIE-Commission Internationale de 1'Eclairage (International Commission of Illumination) CIE.

$\mathrm{L} * \mathrm{a} * \mathrm{~b} *$ system related to CIE standard illuminant D65 was against a white background in the absorption and Reflection Spectrophotometer.

Positioning the specimens on a white background to prevent potential absorption effects performed color measurements.

The surface was scanned at wavelengths from $380 \mathrm{~nm}$ to $780 \mathrm{~nm}$ with the monochromator slit width at $5 \mathrm{~nm}$ and operated at a scan rate of $100 \mathrm{~nm} / \mathrm{min}$ to obtain maximum accuracy.

The instrument was placed in the calibration block holder so that the probe tip was flush with and perpendicular to the calibration block and depressed the block. The device was then automatically calibrated after hearing three audible beeps.

After successful calibration, the measurement menu was displayed, and the "Single sample" measurement mode was selected. The probe tip was positioned directly on the sample covering its entire surface, and the shade was instantly measured.

This equipment is specifically for color measurement and has 30 LED lamps with ten different colors arranged in a circle, which directs a light bundle at $45^{\circ}$ with the material surface. This light bundle is reflected $0^{0}$ to the equipment, which captures and records the $L^{*}, a^{*}$ and $b^{*}$ values of each specimen.

Colors and their values increase for saturated or intense colors.

The baseline measurements $\left(\Delta \mathrm{E}^{*}\right)$ were determined to Hunter'sequation:

$$
\Delta \mathrm{E}^{*}=\left[\left(\Delta \mathrm{L}^{*}\right)^{2}+\left(\Delta \mathrm{a}^{*}\right)^{2}+\left(\Delta \mathrm{b}^{*}\right)^{2}\right]^{1 / 2}
$$

Opacity $(\Delta \mathrm{L})$ and total color change of specimens $(\Delta \mathrm{E})$

Variables were: $\Delta \mathrm{L}^{*}=\mathrm{L}$ initial - Lfinal; $\Delta \mathrm{b}^{*}=a$ initial $-a$ final; $\Delta \mathrm{b}^{*}=b$ initial $-b$ final.

Differences' in the CIE L* $a^{*} b^{*}$ color space; color notation system 
If $\Delta \mathrm{L}^{*+}$ : means specimen after was lighter than before during time intervals.

If $\Delta L^{*}-$ : means specimen after was darker than before during time follow up.

If $\Delta \mathrm{a}^{*+}$ : means specimen after was redder than before during time follow up.

If $\Delta \mathrm{a}^{*}$ - : means specimen after was greener than before during time follow up.

If $\Delta b^{*+}$ : means specimen after was yellower than before during time follow up.

If $\Delta b^{*}$ - : means specimen after was bluer than before during time follow up

The "L" axial is known as luminosity, and it extends from 0 (black) to 100 (perfect white- barium sulfate).

The " $a$ " coordinate represents the quantity of red (positive values) and green (negative values)

The "b" coordinate represents the quantity of yellow (positive values) and blue (negative values).

Mean $\Delta \mathrm{E}^{*}$ values for the experimental groups were calculated between baseline and after immersion.

Where $\Delta$ is the difference between the first and second measurement

The relationship between the amounts of color alteration recorded on a Spectrophotometer to the clinical environment, data was converted to the National Bureau of Standards (NBS) system Table: 3.

The Delta E difference of 1 can be perceived visually by $50 \%$ of human observers

Values $\Delta \mathrm{E}^{*} \geq 3.3$ were considered clinically unacceptable.

The clinically acceptable value for color changes in Dental materials was assumed to be $\Delta \mathrm{E}^{*} \mathrm{ab} \leq$ 3.3. According to this system, $\Delta \mathrm{E}$ values can be described by the following equation:

$$
\text { NBS unit }=\Delta \mathrm{E} \times 0.92 \text {. }
$$

\section{STATISTICAL ANALYSIS}

We calculated the differences in color change by the immersion protocols, and statistical analysis was performed using statistical software SPSS version 22.0.

Descriptive statistics, including the mean, standard deviation, minimum, median, and maximum for each group, were calculated.

A one-way analysis of variance test (ANOVAvariation factors: composite, treatment, and evaluation period) was applied to determine whether significant differences existed among the groups. Tukey's test was used as a post hoc to evaluate pairwise compared.

The color measurements of the experimental specimens (subgroup) were compared with control specimens (subset). Significance was pre-determined at $P<0.001$ The confidence level was $95 \%$.

\section{RESULTS}

Water Absorption (Table- 4)

There was a significant difference in water absorption in Tetric N Ceram. (Table 2) For intragroup comparison Students t-test was used. Statistical analysis of data using t-test between the groups showed that there was a highly significant difference in water absorption with $\mathrm{p}<0.001$.

\section{Surface roughness (Table- 5, 6)}

All the finish protocols in nanohybrid composite recorded a higher surface roughness mean value. The non-finished group recorded the lowest surface roughness. A statistical value analysis of the mean surface roughness revealed that the difference between different finish protocols for the hybrid composite group was significant $(P<0.001)$.

\section{Color Measurement: (Table- 7, 8, 9)}

When the color changes between the subgroups, the maximum discoloration took place on the 28th day of immersion in an energy drink, and results were statistically significant $(\mathrm{p}<0.001)$. Maximum discoloration took place in Blueberry > Carbonated drink-Fanta > Candy Lollipop> Lipstick.

Table-1: Restorative materials, composition, shade and batch numbers (According to manufacturers' data)

\begin{tabular}{|c|c|c|c|c|c|c|c|}
\hline \multirow{3}{*}{ 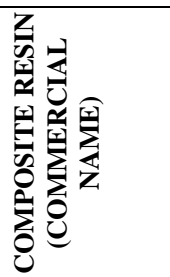 } & \multicolumn{6}{|c|}{ COMPOSITION } & \multirow[b]{3}{*}{ 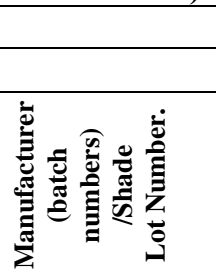 } \\
\hline & \multirow{2}{*}{ 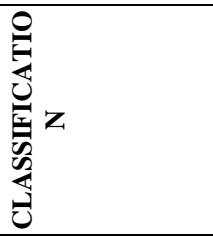 } & \multicolumn{5}{|c|}{ FILLERS } & \\
\hline & & $\sum_{\substack{\vdots \\
\vdots}}^{\substack{\frac{1}{2} \\
\frac{1}{2}}}$ & 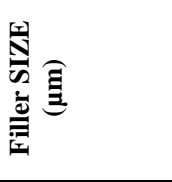 & 恶。 & 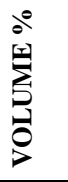 & 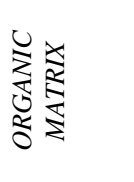 & \\
\hline $\begin{array}{l}\text { TETRIC N } \\
\text { CERAM }\end{array}$ & $\begin{array}{l}\text { NANOHYBRID } \\
\text { COMPOSITE }\end{array}$ & $\begin{array}{c}\text { Barium glass } \\
\text { Ytterbium } \\
\text { Trifluoride } \\
\text { Highly dispersed } \\
\text { silica } \\
\text { Mixed oxide prepolymer }\end{array}$ & $\begin{array}{l}550 \mathrm{~nm} \text { mean } \\
\text { particle size; } \\
\text { range: } 40 \mathrm{~nm} \\
\text { to } 3000 \mathrm{~nm}\end{array}$ & $82-84$ & 64 & $\begin{array}{c}\text { UDMA } \\
\text { Bis-GMA. }\end{array}$ & $\begin{array}{l}\text { Ivoclar vivadent } \\
\text { Schaan, } \\
\text { LiechtenstienA2 } \\
\text { LOT: } \\
\text { W83755 }\end{array}$ \\
\hline
\end{tabular}


Abbervations

- Bis-EMA: Bisphenol A Polyethylene Glycol diether Dimethacrylate.

- UDMA: Urethane Dimethacrylate.

Table-2: You are polishing agents and staining agents

\begin{tabular}{|c|c|c|c|}
\hline Materials & Composition & $\begin{array}{c}\text { Manufacturer } \\
\text { (batch numbers) } \\
\text { Lot Number }\end{array}$ & size \\
\hline \multicolumn{4}{|c|}{ Polishing agents } \\
\hline $\begin{array}{l}\text { SOF-LEX Polishing } \\
\text { Discs }\end{array}$ & Urethane coated paper-Aluminum oxide & $\begin{array}{l}\text { 3M ESPE, St. } \\
\text { Paul, MN, USA } \\
\text { Lot: N } 917009\end{array}$ & $\begin{array}{l}\text { Aluminum oxide, } \\
\text { Grit: Coarse }(40 \\
\mu \mathrm{m}) \quad \text { Medium } \\
(29 \mu \mathrm{m})\end{array}$ \\
\hline $\begin{array}{l}\text { Sof-Lex }{ }^{\mathrm{TM}} \text { Diamond } \\
\text { Polishing System }\end{array}$ & Gorgeous diamond paste- rubberized system & $\begin{array}{c}\text { 3M ESPE, St.Paul, } \\
\text { MN, } \\
\text { USA } \\
\text { Lot: N } 817703\end{array}$ & $0.5 \mu \mathrm{m}$ \\
\hline \multicolumn{4}{|c|}{ Staining agents (Understudy media) } \\
\hline Specimen & Composition & $\begin{array}{l}\text { Manufacturer/ } \\
\text { Brand name }\end{array}$ & pH \\
\hline $\begin{array}{l}\text { Ultra-fixer lipstick } \\
\text { (Batch Red 2000) }\end{array}$ & $\begin{array}{c}\text { Cyclomethicone; Diphenyl; Dimethicone; Polyethylene; } \\
\text { ethylhexyl methoxycinnamate; Acrylates/Stearyl } \\
\text { acrylate/Dimethicone methacrylate copolymer; } \\
\text { cera microcristalina; Isopropryl isostearate; Phenyl } \\
\text { trimethicone; Titaniumdioxide; Acrylates/dimethocone } \\
\text { copolymer; Polymethilsilsequioxisano; Glycerin; Water; } \\
\text { PVP/ } \\
\text { Hexadecenecopolymer; Sucrose distearate; Acrylates } \\
\text { copolymer; perfume; PVM/ MA copolymer; } \\
\text { PVP/Eicosene copolymer; Simmondsia chinensis cera; } \\
\text { Perflurooctyl triethoxysilane; Lecithin/C12-15 alkyl } \\
\text { benzoate/Tocopheryl acetate/Ascorbyl } \\
\text { palmitate/Betacarotene/Retinyl palmitate; Retinyl } \\
\text { palmitate }\end{array}$ & $\begin{array}{l}\text { AVON BEAUTY } \\
\text { PRODUCTS } \\
\text { INDIA PVT.LTD }\end{array}$ & 5.5 \\
\hline $\begin{array}{c}\text { Indian } \\
\text { Blackberries (Syzgium } \\
\text { cumini) juice }\end{array}$ & $100 \%$ Blueberry juice(strained) & Freshly squeezed & 4.5 \\
\hline $\begin{array}{c}\text { Sugar Candy } \\
\text { (Hard candies) }\end{array}$ & $\begin{array}{c}\text { Granulated sugar-99\% } \\
\text { Corn syrup } \\
\text { liquid food coloring agents } \\
\text { Orange kick pop candy Sugar, maltose syrup, carbon dioxide, } \\
\text { sodium bicarbonate, artificial flavor, } \\
\text { color (E129) }\end{array}$ & $\begin{array}{l}\text { Evergreen sweets } \\
\text { G/A-93, Food } \\
\text { Grains Market, } \\
\text { Koyambedu, } \\
\text { Chennai, Tamil } \\
\text { Nadu, India. }\end{array}$ & 4.5 \\
\hline $\begin{array}{l}\text { Carbonated drink- } \\
\text { Fanta }\end{array}$ & $\begin{array}{c}\text { Carbonated water } \\
\text { Sugar (sucrose or high-fructose corn syrup (HFCS) } \\
\text { depending on the country of origin) } \\
\text { Caffeine } \\
\text { Phosphoric acid } \\
\text { Caramel color (E150d) } \\
\text { Natural flavorings } \\
\text { Carbonated water, High fructose corn syrup, Caramel color, } \\
\text { Phosphoric acid, Natural flavors, Caffeine. }\end{array}$ & $\begin{array}{l}\text { Hindustan cola } \\
\text { cola } \\
\text { Beverages Pvt } \\
\text { Ltd, Thiruvallur } \\
\text { Dist. } \\
\text { Fanta } \\
\text { Lot: } \\
\text { BNH10C1019 }\end{array}$ & 2.73 \\
\hline
\end{tabular}

Table-3: National Bureau of Standards (NBS) system of expressing color differences.

\begin{tabular}{|c|c|}
\hline$\Delta \mathbf{E}$ & NBS Criteria \\
\hline $0-0.5$ & Trace: Remarkably slight alteration \\
\hline $0.5-1.5$ & Slight: slight alteration \\
\hline $1.5-3$ & Noticeable: Observable alteration \\
\hline $3-6$ & Appreciable: Apparent alteration \\
\hline $6-12$ & Much: Remarkably apparent alteration \\
\hline 12 or more & Very much: Alteration to another color \\
\hline
\end{tabular}


K. Srinivasan; Saudi J Oral Dent Res, Feb 2020; 5(2): 127-141

Table-4: Water Uptake

\begin{tabular}{|c|c|c|c|c|c|}
\hline & & Lipstick (\%) & Blackberry (\%) & Candy Lollipop (\%) & Carbonated drink-Fanta (\%) \\
\hline Baseline & & \multicolumn{4}{|c|}{$0.80 \mu \mathrm{g} / \mathrm{mm}^{3}$} \\
\hline \multirow[t]{3}{*}{15 days } & Group- I & $0.80 \mu \mathrm{g} / \mathrm{mm}^{3}(0 \%)$ & $\begin{array}{c}0.85 \mu \mathrm{g} / \mathrm{mm}^{3} \\
(15 \%)\end{array}$ & $0.90 \mu \mathrm{g} / \mathrm{mm}^{3}(15.8 \%)$ & $0.94 \mu \mathrm{g} / \mathrm{mm}^{3}(16.6 \%)$ \\
\hline & Group - II & $0.80 \mu \mathrm{g} / \mathrm{mm}^{3}(0 \%)$ & $\begin{array}{c}0.87 \mu \mathrm{g} / \mathrm{mm}^{3} \\
(15.3 \%)\end{array}$ & $0.88 \mu \mathrm{g} / \mathrm{mm}^{3}(14 \%)$ & $0.91 \mu \mathrm{g} / \mathrm{mm}^{3}(16 \%)$ \\
\hline & Group - III & $0.80 \mu \mathrm{g} / \mathrm{mm}^{3}(0 \%)$ & $\begin{array}{c}0.84 \mu \mathrm{g} / \mathrm{mm}^{3} \\
(14.9 \%)\end{array}$ & $0.85 \mu \mathrm{g} / \mathrm{mm}^{3}(14.9 \%)$ & $0.90 \mu \mathrm{g} / \mathrm{mm}^{3}(15.8 \%)$ \\
\hline
\end{tabular}

Table-5: Mean (SD) values for surface roughness $(\mathrm{Ra})(\mathrm{n}=60)$

\begin{tabular}{|c|c|c|c|c|c|c|}
\hline & & & \multicolumn{3}{|c|}{ ANOVA } & \multirow[b]{2}{*}{$\begin{array}{l}\text { Statistical } \\
\text { inference }\end{array}$} \\
\hline \multicolumn{2}{|c|}{ Variable } & $\mathbf{n}$ & $\begin{array}{c}\text { Mean } \pm \text { SD } \\
\text { Comparisons }\end{array}$ & $\begin{array}{c}\mathrm{Z} \text { - value } \\
\text { Comparisons }\end{array}$ & p-value & \\
\hline \multicolumn{7}{|c|}{ LIPSTICK } \\
\hline \multirow[t]{2}{*}{ Group I } & Baseline & \multirow[t]{2}{*}{5} & \multirow[t]{2}{*}{$0.11 \pm 7.071$} & \multirow[t]{2}{*}{0.69} & \multirow[t]{2}{*}{$\mathrm{p}=0.48$} & \multirow[t]{2}{*}{ NS } \\
\hline & 15 days & & & & & \\
\hline \multirow[t]{2}{*}{ Group II } & Baseline & \multirow[t]{2}{*}{5} & \multirow[t]{2}{*}{$0.29 \pm 7.071$} & \multirow[t]{2}{*}{0.66} & & \multirow[t]{2}{*}{ NS } \\
\hline & 15 days & & & & & \\
\hline \multirow[t]{2}{*}{ Group III } & Baseline & \multirow[t]{2}{*}{5} & \multirow[t]{2}{*}{$0.20 \pm 7.071$} & \multirow[t]{2}{*}{0.67} & \multirow[t]{2}{*}{$\mathrm{p}=0.50$} & \multirow[t]{2}{*}{ NS } \\
\hline & 15 days & & & & & \\
\hline \multicolumn{7}{|c|}{ BLUEBERRY } \\
\hline \multirow[t]{2}{*}{ Group I } & Baseline & 5 & \multirow[t]{2}{*}{$0.11 \pm 0.0014$} & \multirow[t]{2}{*}{3457.07} & \multirow[t]{2}{*}{$\mathrm{p}<0.0001$} & \multirow[t]{2}{*}{ HS } \\
\hline & 15 days & & & & & \\
\hline \multirow[t]{2}{*}{ Group II } & Baseline & \multirow[t]{2}{*}{5} & \multirow[t]{2}{*}{$0.58 \pm 0.0056$} & \multirow[t]{2}{*}{1561.52} & $\mathrm{p}<0.0001$ & HS \\
\hline & 15 days & & & & & \\
\hline Group III & Baseline & 5 & $0.20 \pm 0.0028$ & 1696.60 & $\mathrm{p}<0.0001$ & HS \\
\hline & 15 days & & & & & \\
\hline & & & ANDY LOLLII & & & \\
\hline Group I & Baseline & 5 & $0.11 \pm 0.00141$ & 3457.07 & $\mathrm{p}<0.0001$ & HS \\
\hline & 15 days & & & & & \\
\hline Group II & Baseline & 5 & $0.29 \pm 0.0056$ & 532.03 & $\mathrm{p}<0.0001$ & HS \\
\hline & 15 days & & & & & \\
\hline Group III & Baseline & 5 & $0.20 \pm 0.0028$ & 1696.60 & $\mathrm{p}<0.0001$ & HS \\
\hline & 15 days & & & & & \\
\hline & & & ONATED DRIN & & & \\
\hline Group I & Baseline & 5 & $0.11 \pm 0.0028$ & 1228.42 & $\mathrm{p}<0.0001$ & HS \\
\hline & 15 days & & & & & \\
\hline Group II & Baseline & 5 & $0.296 \pm 0.0084$ & 554.37 & $\mathrm{p}<0.0001$ & HS \\
\hline & 15 days & & & & & \\
\hline Group III & Baseline & 5 & $0.20 \pm 0.0056$ & 847.94 & $\mathrm{p}<0.0001$ & HS \\
\hline & 15 days & & & & & \\
\hline
\end{tabular}

Statistical Inference: HS-Highly significant; NS-Not significant; SS-Statistical significant.

Table-6: Surface roughness- Multiple Comparisons Using Tukey HSD Analysis (n=60)

\begin{tabular}{|c|c|c|c|c|}
\hline Variable & t-test & 95\% Confidence Interval & Two tests- p-Value & $\begin{array}{l}\text { Statistical } \\
\text { Inference }\end{array}$ \\
\hline \multicolumn{5}{|c|}{ LIPSTICK } \\
\hline Group I \& II & 0.040 & -10.49 to 10.132 & $\mathrm{p}=0.968$ & $\mathrm{NS}$ \\
\hline Group I \& III & 0.020 & -10.40 to -10.222 & $\mathrm{p}=0.984$ & NS \\
\hline Group II \& III & 0.020 & -10.22 to 10.402 & $\mathrm{p}=0.984$ & NS \\
\hline \multicolumn{5}{|c|}{ BLUEBERRY } \\
\hline Group I \& II & 334.60 & -0.47 to -0.469 & $\mathrm{p}<0.0001$ & $\mathrm{HS}$ \\
\hline Group I \& III & 64.37 & -0.094 to -0.087 & $\mathrm{p}<0.0001$ & HS \\
\hline Group II \& III & 270.23 & -0.37 to 0.385 & $\mathrm{p}<0.0001$ & $\mathrm{HS}$ \\
\hline \multicolumn{5}{|c|}{ CANDY LOLLIPOP } \\
\hline Group I \& II & 70.19 & -0.18 to -0.176 & $\mathrm{p}<0.0001$ & HS \\
\hline Group I \& III & 64.37 & -0.094 to -0.087 & $\mathrm{p}<0.0001$ & HS \\
\hline Group II \& III & 75.27 & -202 to 1902 & $\mathrm{p}<0.0001$ & $\mathrm{HS}$ \\
\hline \multicolumn{5}{|c|}{ CARBONATED DRINK-FANTA } \\
\hline Group I \& II & 46.002 & -0.19 to -0.174 & $\mathrm{p}<0.0001$ & HS \\
\hline Group I \& III & 32.53 & -0.098 to -0.085 & $\mathrm{p}<0.0001$ & HS \\
\hline Group II \& III & 20.17 & 0.81 to 0.102 & $\mathrm{p}<0.0001$ & $\mathrm{HS}$ \\
\hline
\end{tabular}


K. Srinivasan; Saudi J Oral Dent Res, Feb 2020; 5(2): 127-141

Table-7: GROUP II - Nano Hybrid Composite Values before and after Exposure to Stains (n=60) LIPSTICK

\begin{tabular}{|c|c|c|c|c|c|c|c|}
\hline \multirow[t]{3}{*}{ lipstick } & \multicolumn{3}{|c|}{ GROUP II- BASELINE VALUES (Mean) } & \multicolumn{4}{|c|}{ GROUP II- AFTER 15 DAYS VALUES (Mean) } \\
\hline & $\Delta \mathrm{L}_{1}$ & $\Delta \mathrm{a}_{1}$ & $\Delta b_{1}$ & $\Delta \mathrm{L}_{2}$ & $\Delta \mathrm{a}_{2}$ & $\Delta b_{2}$ & $\Delta \mathrm{E}$ \\
\hline & 73.63 & 0.812 & 9.78 & 75.34 & 0.84 & 10.14 & 1.49 \\
\hline \multicolumn{8}{|c|}{ BLUEBERRY } \\
\hline \multirow[t]{3}{*}{ Blueberry } & \multicolumn{3}{|c|}{ GROUP II- BASELINE VALUES (Mean) } & \multicolumn{4}{|c|}{ GROUP II- AFTER 15 DAYS VALUES (Mean) } \\
\hline & $\Delta \mathrm{L}_{1}$ & $\Delta \mathrm{a}_{1}$ & $\Delta b_{1}$ & $\Delta \mathrm{L}_{2}$ & $\Delta \mathrm{a}_{2}$ & $\Delta b_{2}$ & $\Delta \mathrm{E}$ \\
\hline & 74.48 & 0.85 & 9.76 & 57.97 & 0.83 & 15.11 & 6.03 \\
\hline \multicolumn{8}{|c|}{ CANDY LOLLIPOP } \\
\hline \multirow{3}{*}{$\begin{array}{l}\text { Candy } \\
\text { Lollipop }\end{array}$} & \multicolumn{3}{|c|}{ GROUP II- BASELINE VALUES (Mean) } & \multicolumn{4}{|c|}{ GROUP II- AFTER 15 DAYS VALUES (Mean) } \\
\hline & $\Delta \mathrm{L}_{1}$ & $\Delta \mathrm{a}_{1}$ & $\Delta b_{1}$ & $\Delta \mathrm{L}_{2}$ & $\Delta \mathrm{a}_{2}$ & $\Delta b_{2}$ & $\Delta \mathrm{E}$ \\
\hline & 74.36 & 0.83 & 9.67 & 75.86 & 0.77 & 7.99 & 2.08 \\
\hline \multicolumn{8}{|c|}{ CARBONATED DRINK -FANTA } \\
\hline \multirow{3}{*}{$\begin{array}{c}\text { Carbonated } \\
\text { drink } \\
\text {-Fanta }\end{array}$} & \multicolumn{3}{|c|}{ GROUP II- BASELINE VALUES (Mean) } & \multicolumn{4}{|c|}{ GROUP II- AFTER 15 DAYS VALUES (Mean) } \\
\hline & $\Delta \mathrm{L}_{1}$ & $\Delta \mathrm{a}_{1}$ & $\Delta b_{1}$ & $\Delta \mathrm{L}_{2}$ & $\Delta \mathrm{a}_{2}$ & $\Delta b_{2}$ & $\Delta \mathrm{E}$ \\
\hline & 74.04 & 0.83 & 9.80 & 73.15 & 0.38 & 10.92 & 3.14 \\
\hline
\end{tabular}

Table-8: GROUP III - Nano Hybrid Composite Values before and after Exposure to Stains (n=60)

\begin{tabular}{|c|c|c|c|c|c|c|c|}
\hline \multicolumn{8}{|c|}{ LIPSTICK } \\
\hline \multirow[t]{3}{*}{ lipstick } & \multicolumn{3}{|c|}{ GROUP III- BASELINE VALUES (Mean) } & \multicolumn{4}{|c|}{ GROUP III- AFTER 15 DAYS VALUES (Mean) } \\
\hline & $\Delta \mathbf{L}_{1}$ & $\Delta \mathbf{a}_{1}$ & $\Delta b_{1}$ & $\Delta \mathbf{L}_{2}$ & $\Delta \mathbf{a}_{2}$ & $\Delta b_{2}$ & $\Delta \mathbf{E}$ \\
\hline & 74.12 & 0.83 & 9.69 & 75.50 & 0.84 & 9.85 & 1.46 \\
\hline \multicolumn{8}{|c|}{ BLUEBERRY } \\
\hline \multirow[t]{3}{*}{ Blueberry } & \multicolumn{3}{|c|}{ GROUP III- BASELINE VALUES (Mean) } & \multicolumn{4}{|c|}{ GROUP III- AFTER 15 DAYS VALUES (Mean) } \\
\hline & $\Delta \mathrm{L}_{1}$ & $\Delta \mathrm{a}_{1}$ & $\Delta b_{1}$ & $\Delta \mathrm{L}_{2}$ & $\Delta \mathrm{a}_{2}$ & $\Delta b_{2}$ & $\Delta \mathrm{E}$ \\
\hline & 74.66 & 0.82 & 10.06 & 73.57 & 0.85 & 14.20 & 5.05 \\
\hline \multicolumn{8}{|c|}{ CANDY LOLLIPOP } \\
\hline \multirow{3}{*}{$\begin{array}{c}\text { Candy } \\
\text { Lollipop }\end{array}$} & \multicolumn{3}{|c|}{ GROUP III- BASELINE VALUES (Mean) } & \multicolumn{4}{|c|}{ GROUP III- AFTER 15 DAYS VALUES (Mean) } \\
\hline & $\Delta \mathrm{L}_{1}$ & $\Delta \mathrm{a}_{1}$ & $\Delta b_{1}$ & $\Delta \mathrm{L}_{2}$ & $\Delta \mathrm{a}_{2}$ & $\Delta b_{2}$ & $\Delta \mathrm{E}$ \\
\hline & 74.02 & 0.81 & 9.79 & 75.45 & 0.90 & 10.09 & 1.40 \\
\hline \multicolumn{8}{|c|}{ CARBONATED DRINK -FANTA } \\
\hline \multirow{3}{*}{$\begin{array}{c}\text { Carbonated } \\
\text { drink } \\
\text {-Fanta }\end{array}$} & \multicolumn{3}{|c|}{ GROUP III- BASELINE VALUES (Mean) } & \multicolumn{4}{|c|}{ GROUP III- AFTER 15 DAYS VALUES (Mean) } \\
\hline & $\Delta \mathrm{L}_{1}$ & $\Delta \mathrm{a}_{1}$ & $\Delta b_{1}$ & $\Delta \mathrm{L}_{2}$ & $\Delta \mathrm{a}_{2}$ & $\Delta b_{2}$ & $\Delta \mathrm{E}$ \\
\hline & 75.51 & 0.82 & 9.88 & 74.20 & 0.52 & 9.18 & 2.16 \\
\hline
\end{tabular}

Table-9: Staining agents-Multiple Comparisons using Tukey HSD analysis $(\mathrm{n}=60)$

\begin{tabular}{|c|c|c|c|c|c|c|c|}
\hline $\begin{array}{c}\text { Dependent } \\
\text { variable }\end{array}$ & Group & Inter groups & Mean \pm SD & $\begin{array}{c}\text { 95\% Confidence } \\
\text { Interval }\end{array}$ & t-TEST & $\begin{array}{l}\text { Two tests- } \\
\text { p-Value }\end{array}$ & $\begin{array}{l}\text { Statistical } \\
\text { Inference }\end{array}$ \\
\hline \multirow{12}{*}{ 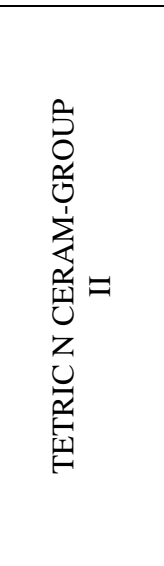 } & \multirow{3}{*}{ lipstick } & Blueberry & $6.036 \pm 0.426$ & -5.356 to-3.727 & 12.854 & $\mathrm{P}<0.0001$ & HS \\
\hline & & Candy Lollipop & $1.622 \pm 1.312$ & -1.645 to 1.389 & 0.194 & $\mathrm{P}=0.85$ & NS \\
\hline & & $\begin{array}{l}\text { Carbonated } \\
\text { drink-Fanta }\end{array}$ & $3.144 \pm 0.648$ & -2.607 to- 0.692 & 3.972 & $\mathrm{P}<0.0001$ & HS \\
\hline & \multirow[t]{3}{*}{ Blueberry } & Lipstick & $1.494 \pm 0.665$ & 3.727 to5.356 & 12.860 & $\mathrm{P}<0.0001$ & HS \\
\hline & & Candy Lollipop & $1.622 \pm 1.312$ & 2.991to5.836 & 7.155 & $\mathrm{P}<0.0001$ & $\mathrm{HS}$ \\
\hline & & $\begin{array}{l}\text { Carbonated } \\
\text { drink-Fanta }\end{array}$ & $3.144 \pm 0.648$ & 2.0922 to3.691 & 8.338 & $\mathrm{P}<0.0001$ & HS \\
\hline & \multirow{3}{*}{$\begin{array}{c}\text { Candy } \\
\text { Lollipop }\end{array}$} & Lipstick & $1.494 \pm 0.665$ & -1.388 to1.644 & 0.194 & $\mathrm{P}=0.85$ & NS \\
\hline & & Blueberry & $6.036 \pm 0.426$ & -5.836 to-2.991 & 7.155 & $\mathrm{P}<0.0001$ & HS \\
\hline & & $\begin{array}{l}\text { Carbonated } \\
\text { drink-Fanta }\end{array}$ & $3.144 \pm 0.648$ & -3.031 to- 0.012 & 2.325 & $\mathrm{P}=0.48$ & SS \\
\hline & \multirow{3}{*}{$\begin{array}{l}\text { Carbonated } \\
\text { drink-Fanta }\end{array}$} & Lipstick & $1.494 \pm 0.665$ & 0.692 to 2.607 & 3.973 & $\mathrm{P}=0.0041$ & SS \\
\hline & & Blueberry & $6.036 \pm 0.426$ & -3.691 to-2.092 & 8.333 & $\mathrm{P}<0.0001$ & $\mathrm{HS}$ \\
\hline & & Candy Lollipop & $1.622 \pm 1.312$ & 0.012 to3.031 & 2.325 & $\mathrm{P}=0.048$ & SS \\
\hline \multirow{5}{*}{ 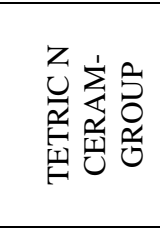 } & \multirow[t]{3}{*}{ lipstick } & Blueberry & $5.112 \pm 0.331$ & -4.526 to- 2.777 & 9.631 & $\mathrm{P}<0.0001$ & HS \\
\hline & & Candy Lollipop & $1.406 \pm 0.790 \mathrm{~F}$ & -1.091 to 1.193 & 0.108 & $\mathrm{P}=0.91$ & NS \\
\hline & & $\begin{array}{l}\text { Carbonated } \\
\text { drink-Fanta }\end{array}$ & $2.168 \pm 0.760$ & -1.831 to 0.415 & 1.453 & $\mathrm{P}=0.184$ & NS \\
\hline & \multirow[t]{2}{*}{ Blueberry } & Lipstick & $1.46 \pm 0.780$ & 2.778 to 4.525 & 9.637 & $\mathrm{P}<0.0001$ & $\mathrm{HS}$ \\
\hline & & Candy Lollipop & $1.406 \pm 0.790$ & 2.822 to 4.589 & 4.674 & $\mathrm{P}<0.0001$ & $\mathrm{HS}$ \\
\hline
\end{tabular}


K. Srinivasan; Saudi J Oral Dent Res, Feb 2020; 5(2): 127-141

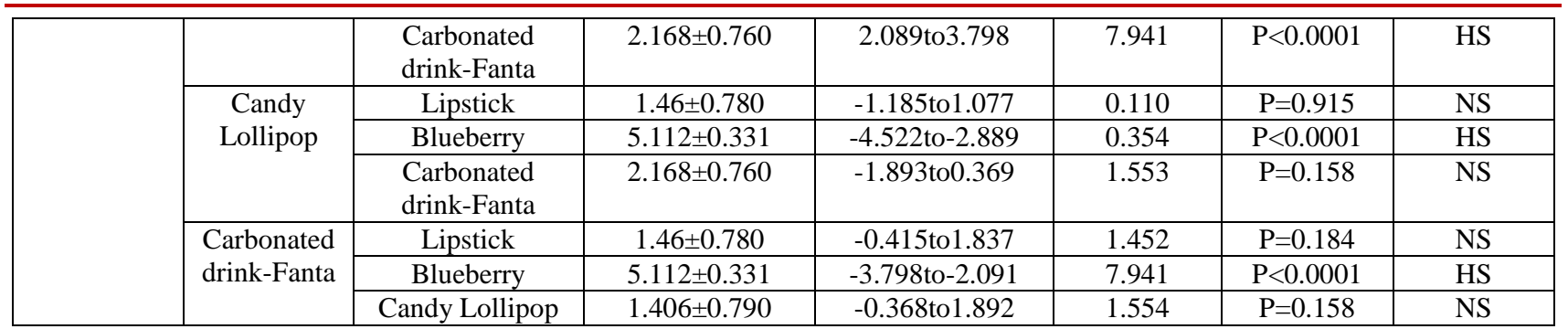

Statistical Inference: HS-Highly significant; NS-Not significant; SS-Statistical significant

\section{Table legends}

- Table .1.Restorative materials, composition, shade, and batch numbers.

- Table.2.Polishing Agents Staining Agents.

- Table. 3. National Bureau of Standards (NBS) system of expressing color differences.

- Table.5.Mean (SD) values for surface roughness (Ra).

- Table.6.Surface roughness- Multiple Comparisons Using Tukey HSD analysis.

- Table. 7. GROUP II - Nano Hybrid Composite Values before and after Exposure to Stains.

- Table. 8. GROUP III - Nano Hybrid Composite Values before and after Exposure to Stains.

- Table.9. Staining agents-Multiple Comparisons using Tukey HSD analysis.

Flowchart-1: Schematic Representation of Distribution of Specimen

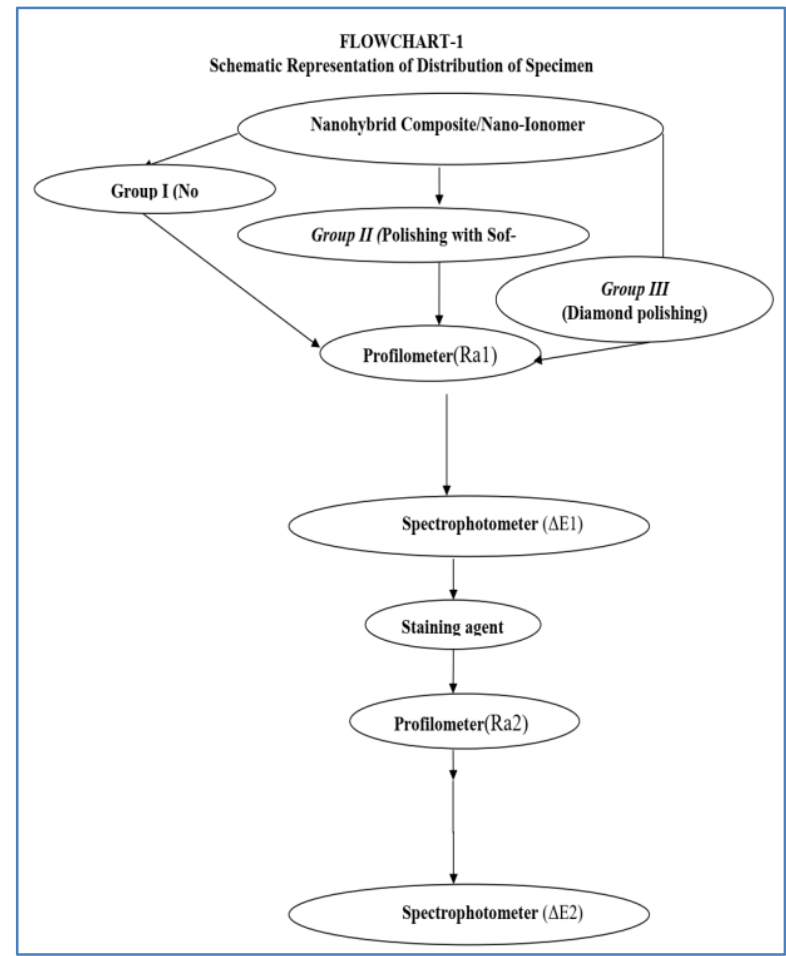

Table legends/capitations

- Table 1: Restorative materials, composition, shade, and batch numbers (According to manufacturers' data.)

- Table 2: Polishing agents staining agents.

- Table: 3.National Bureau of Standards (NBS) system of expressing color differences.

- Flowchart-1.Schematic Representation of Distribution of Specimen.

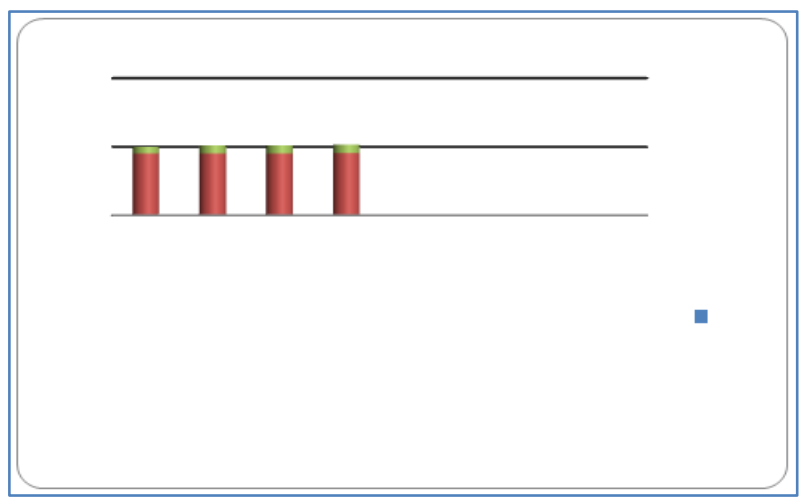

Water uptake - filtek z350xt (nano composite) values before and after exposure- $(\mathbf{n}=60)$

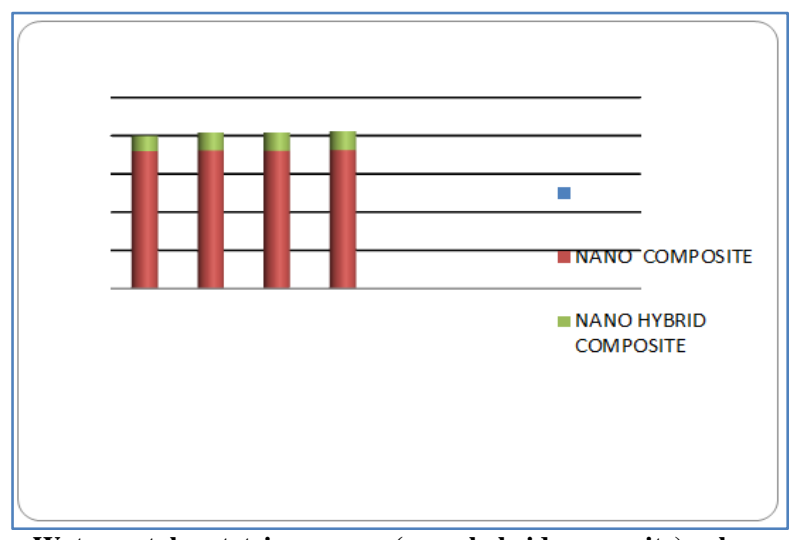

Water uptake - tetric n ceram (nano hybrid composite) values before and after exposure 


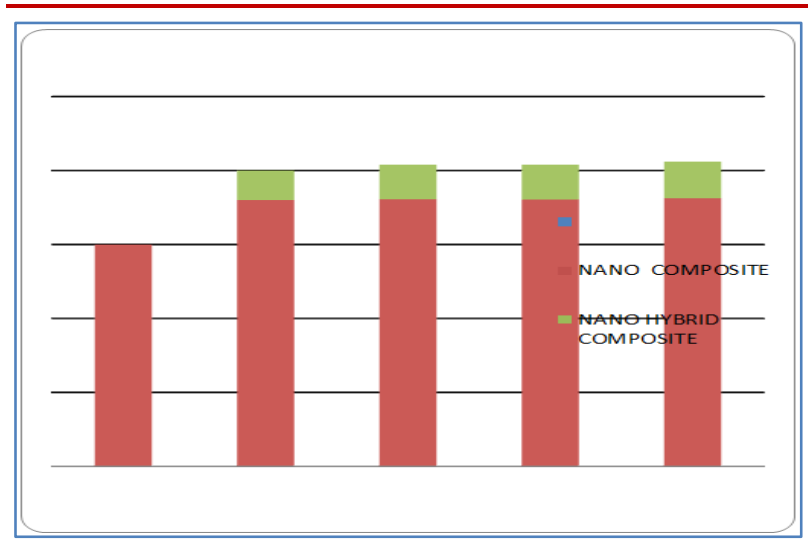

Group- i > <ii > <iii filtek z350xt (nano composite) values before and after exposure-surface hardness

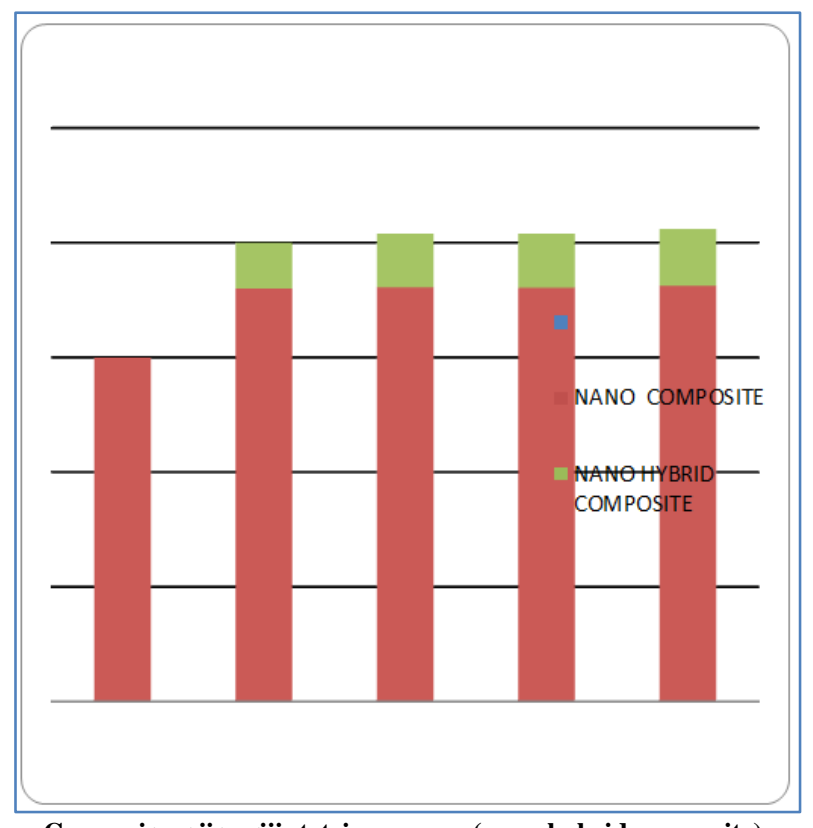

Group- i > < ii > <iii -tetric n ceram (nano hybrid composite) values before and after exposure-(n=60)- surface hardness

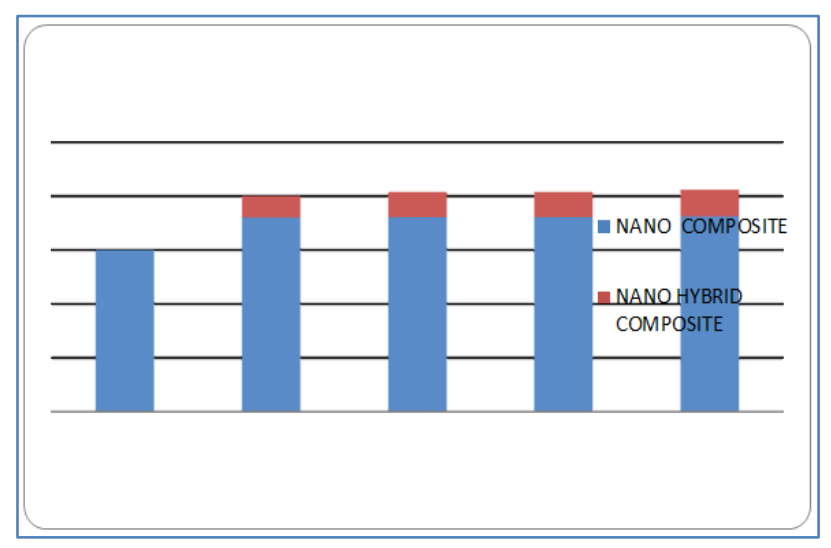

Nano composite $><$ nano hybrid composite group-ii-surface hardness

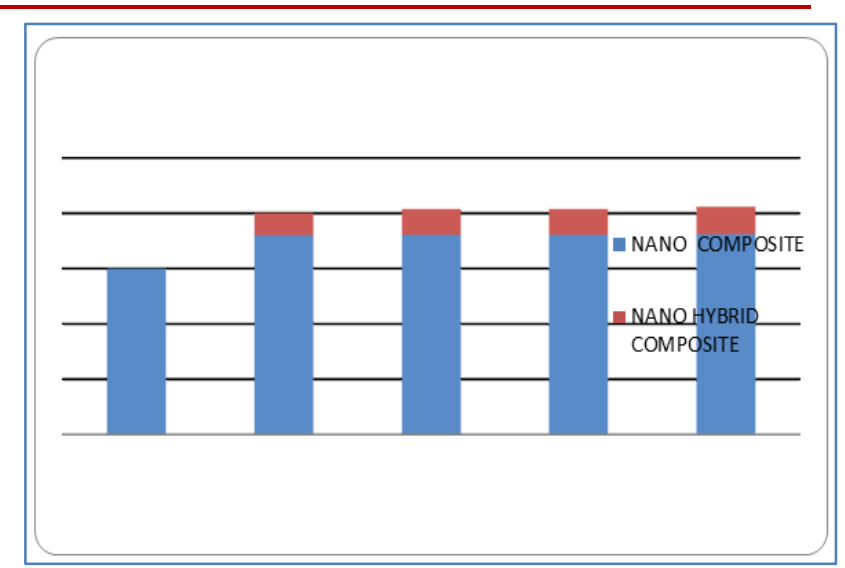

Nano composite $><$ nano hybrid composite group-iii-surface hardness

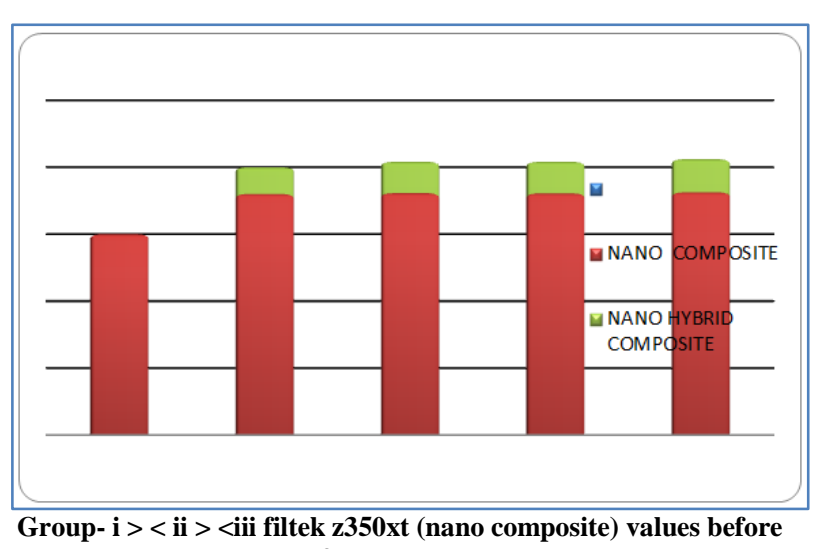
and after exposure-color

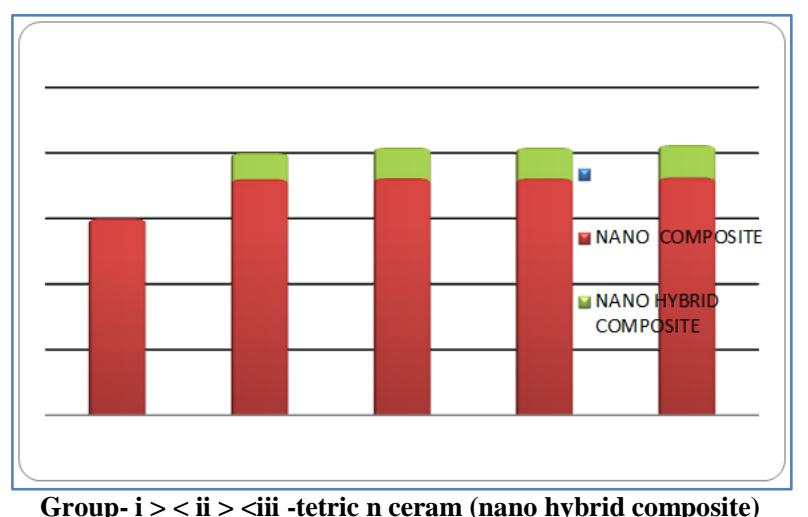

Group- $\mathrm{i}><$ ii $><$ iii -tetric n ceram (nano hybrid composite) values before and after exposure-(n=60)-color

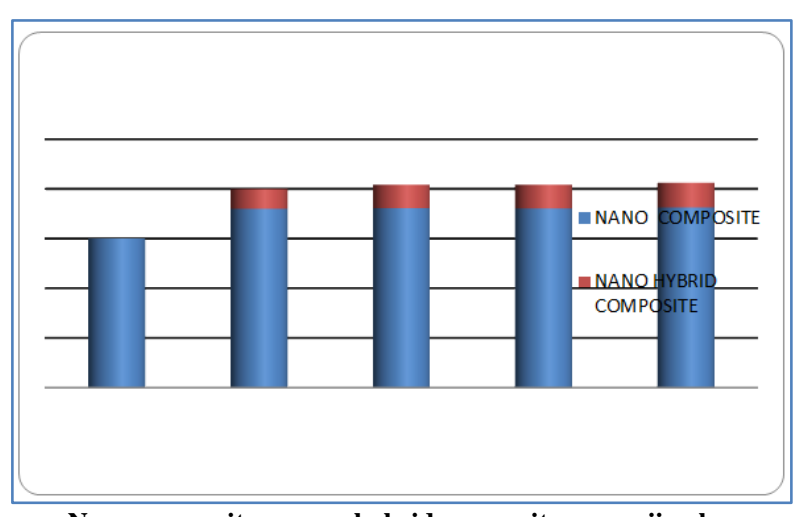

Nano composite ><nano hybrid composite group-ii-color 


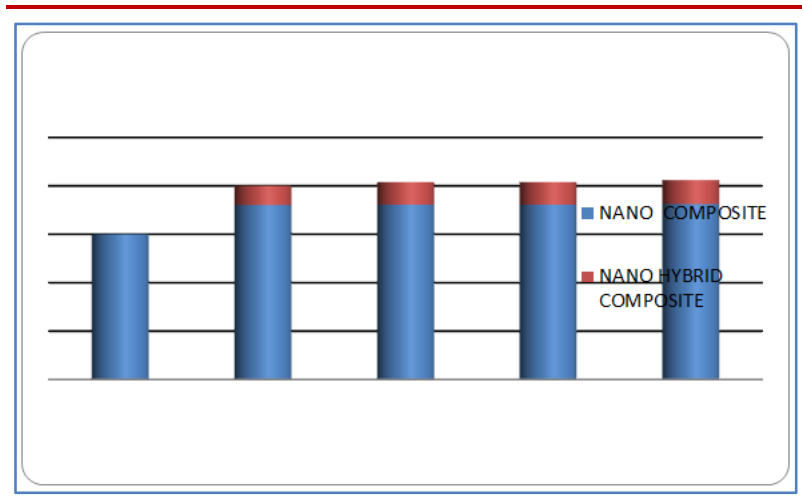

Nano composite ><nano hybrid composite group-iii-color

\section{DISCUSSION}

Saliva is a dilute fluid consisting of $99.5 \%$ of water, hence weight change of different composites were evaluated in water. The concentrations of dissolved solids (organic or inorganic) in saliva are characterized by wide variations, both between individuals and within a single individual. Due to this variation, the test standard was water [23].

Tetric N-Ceram showed higher water absorption. The monomers in these materials are hydrophilic due to the presence of polar groups in their structure which tends to be attracted by water molecules to form hydrogen bonding

Knobloch et al. [24] did the study; Key et al. [25] and Hegde et al. [26] also showed a maximum amount of water absorption in Tetric N-Ceram

Composite resins have been widely used since their introduction as they possess excellent esthetic properties. Recent development includes the addition of Nano-sized fillers to the resin matrix, which gives the composite resin the handling properties, polishing ability. [28].

We conducted a present study on one resin composites and four staining agents. In this study, we wanted the surface roughness assessment because surface micromorphology would affect the staining susceptibility. The CIEL*a*b* system for measuring the chromaticity was chosen to record color differences because it is well suited for the determination of small color differences.

In the present study, the test samples were exposed to commonly consumed beverages such as lipstick, Blackberry, Candy Lollipop, Fanta, in solution form. The samples were subjected to the solutions intermittently and stored in artificial saliva continuously in an incubator at $37^{\circ} \mathrm{C}$ to simulate natural conditions.

Color stability is also dependent upon the surface roughness of the composite restoration, as increased roughness $(>0.3 \mu \mathrm{m})$ may lead to higher plaque retention and stain absorption than relatively smooth surfaces [28].

The results obtained in the present study showed that all samples underwent some changes in color from the baseline value.

The highest color change in all groups was caused due to the blueberry $(P>0.001)$. With a $\Delta \mathrm{E}$ value $>3.3$ in all groups, indicating a visually perceptible, unacceptable color change. The results obtained are per the study conducted by Gupta and Gupta [29] Malhotra et al. [30].

Effects of carbonated drink in the present study are in agreement with Patel et al. [31], who stated that Coca-Cola causes a minimal change in color in the composite resins.

The polishing of restorations can be carried out with a variety of instruments. Each of these instruments removes the oxygen inhibited layer of resin to improve color stability and increase surface hardness, but, also leaves behind a varying degree of roughness. Polishing systems compared in the present study include Sof-Lex, Diamond polishing.

It was observed in this study for the nanocomposite resin to show a decrease in the $\Delta \mathrm{E}$ value concerning the polishing procedure.

Removing the outermost resin layer by polishing is essential in achieving a stain-resistant, more esthetically stable surface [32].

In this study, a comparison of color stability between the polished groups showed samples polished with Sof-Lex disks produced a more stain-resistant surface compared to Diamond polishing paste.

This observation could be attributed to the removal of the oxygen inhibited layer, more than due to the reduction of surface roughness by these polishing methods. The Sof-Lexdisks with a larger grit size (coarse and medium) are more useful in removing the surface layer. The Sof-Lex group showed higher mean roughness values $(0.30 \mu \mathrm{m})$ after polishing and most resistant to color change. The diamond polishing paste $(0.21 \mu \mathrm{m})$ and, control group $(0.11 \mu \mathrm{m})$ with the smoothest surface showed most color change.

Among the polished groups, the smoothest surfaces are seen in the diamond polishing paste group compared to the samples polished with the Sof-Lex polishing disks $(P<0.001)$. The hardness of the diamond particles, which enables it to remove both, phases of the composite resin, i.e., the resin matrix and filler particles homogeneously. The above results are similar per Lainovića et al. [33] 
Staining of resins by fluid pigments and beverages is caused by adsorption or absorption (the uptake of substances into or through tissues) of colorants by resins. In this study, results showed that as the immersion time increased, the color changes became more intense. This result was similar to that reported by Abu-Bakr et al. [34].

An increase in surface roughness following immersion in solutions was in the following order: Blackberry > Candy Lollipop > Fanta > lipstick > Control. Samples immersed in Coca Cola showed increased roughness in all groups $(\mathrm{P}<0.001)$.

In this study, the UDMA based resin composite showed significantly more discoloration. The results of the present study provide the importance of polishing procedures and their effect on the restoration. Also, it gives an idea about the impact of the commonly consumed food and beverages on the color stability and surface profile of the restoration. Knowledge of these factors allows the clinician to select the appropriate polishing system and also inform the patient to limit the consumption of food, beverages, and cosmetics detrimental to the restoration.

\section{LIMITATIONS}

An increased number of specimens and restorative materials could improve the validity of the present method.

\section{Clinical Significance}

Despite many improvements in chemical compositions and fillers of the contemporary resin Composites, the color changes after aging were still perceptible in all the resin composites, regardless of their types and brands. Such changes may cause esthetic problems clinically, thus should be taken into account.

\section{CONCLUSION}

Under the conditions of the current study, the following outcomes could be secure.

- Surface Roughness was affected by both material type and storage solutions.

- All efforts should be made to minimize the discoloration of Composite restorations by adopting excellent polishing techniques.

- Patients should also be educated on the possibility of the restoration to undergo staining under the influence of beverages

- The storage condition strongly influences the color of all tested resin-Composites with the wet condition disturbing color more than the dry one, independent of the composite type or the storage period.

- Except for control, all solutions caused a significant change in the color of Composite resin specimens during the study period, and the most significant color change was due to blueberry.

\section{Conflict of interest $\&$ source of funding}

The author declares that there is no exceptional financial support for this research work from the funding agency and there is no conflict of interest among all authors.

\section{ACKNOWLEDGMENT}

The author express sincere gratitude to all respondents whose honest attention help and support, and the participants of the study lead the Research project to the worthful outcome. This study was without any priorities or interest for any of the products in the market.

\section{REFERENCES}

1. Bayne, S.C. (2013). Beginnings of the composite dental revolution. J Am Dent Ass, 144, 8: 880-884.

2. Suddick, R.P., Harris, N.O. (1990). Historical perspectives of oral biology - a series. Crit Rev Oral Biol Med, 1(2):135-51.

3. Harald, O. Heymann, E.J. Swift, Andre, V. Ritter. Sturdevant's Art and Science of Operative Dentistry.

4. Antonucci, J.M., Dickens, S.H., Fowler, B.O. (2005). Chemistry of Silanes: Interfaces in Dental Polymers and Composites. J Res Natl Inst Stand Techno, 110:541- 558.

5. Anusavice, K.J., Shen, C., Rawls, H.R. Phillip's Science of Dental materials; in the $12^{\text {th }}$ edition.

6. Mitra, S.B., Wu, D., Holmes, B.N. (2003). An application of nanotechnology in advanced dental materials. J Am Dent Assoc, 134(10):1382-90.

7. Guifem, E., Smia Mutlu-Sagesen, L., Yalcin, O., \& Erold, E. (2005). In vitro color stability of provisional crown and bridge restoration. Dental Materials Journal, 24(3):342-350.

8. Sarac, D., Sarac, Y.S., Kulunk, S., Ural, C., Kulunk, T. (2006). The effect of polishing techniques on the surface roughness and color change of composite resins. J Prosthet Dent, 96:3340.

9. Behnaz, E., Shaghayegh, R., Mahdie, P., Ali, B., Hoda, A. (2014). Comparative evaluation of the effect of Light Emitting Diode (LED) and Quartz Tungsten Halogen (QTH) light-curing units on color stability of Filtek Z350 XT. Caspian J Dent Res, 3:41-6.

10. Vishal, J.V.J., Jeffrey, Platt, A., Keith, M., Ana, M. Spohr, \& Gilberto, A. (2013). Borges. Color stability, gloss, and surface roughness of indirect composite resins. Journal of Oral Science, 55(1):91

11. AL QAISI, S. D. (2015). Evaluating the Effect of One Alcoholic and Two Alcoholic-free Mouthwashes on the Color Stability and Surface Roughness of Two Resinbased composites (In vitro Comparative Study).

12. Ahmadizenouz, G., Esmaeili, B., Ahangari, Z., Khafri, S., \& Rahmani, A. (2016). Effect of Energy 
Drinks on Discoloration of Silorane and Dimethacrylate-Based Composite Resins. Journal of dentistry (Tehran, Iran), 13(4), 261.

13. De Moraes, R. R., Marimon, J. L. M., Jochims Schneider, L. F., Sinhoreti, M. A. C., CorrerSobrinho, L., \& Bueno, M. (2008). Effects of 6 months of aging in water on hardness and surface roughness of two microhybrid dental composites. Journal of Prosthodontics, 17(4), 323326.

14. Kohli, S., \& Bhatia, S. (2015). Evaluation of the color durability of acrylic resin veneer materials after immersion in common beverages at different time intervals: A spectrophotometric study. Biomedical journal, 38(3).

15. Nuaimi, H., \& Garg, P. (2014). Color stability of nano resin based composite with novel monomer after three months storing. International Journal of Dental and Health Sciences, 1, 112-120.

16. Lee, Y. K., Lim, B. S., \& Kim, C. W. (2002). Effect of surface conditions on the color of dental resin composites. Journal of Biomedical Materials Research: An Official Journal of The Society for Biomaterials, The Japanese Society for Biomaterials, and The Australian Society for Biomaterials and the Korean Society for Biomaterials, 63(5), 657-663.

17. Gupta, G., \& Gupta, T. (2011). Evaluation of the effect of various beverages and food material on the color stability of provisional materials-An in vitro study. Journal of conservative dentistry: JCD , 14(3), 287.

18. Garoushi, S., Lassila, L., Hatem, M., Shembesh, M., Baady, L., Salim, Z., \& Vallittu, P. (2013). Influence of staining solutions and whitening procedures on discoloration of hybrid composite resins. Acta Odontologica Scandinavica, 71(1), 144-150.

19. Tanthanuch, S., Kukiattrakoon, B., Peerasukprasert, T., Chanmanee, N., Chaisomboonphun, P., \& Rodklai, A. (2016). The effect of red and white wine on color changes of nanofilled and nanohybrid resin composites. Restorative dentistry \& endodontics, 41(2), 130-136.

20. Ciccone-Nogueira, J. C., Borsatto, M. C., SouzaZaron, W. C. D., Ramos, R. P., \& Palma-Dibb, R. G. (2007). Microhardness of composite resins at different depths varying the post-irradiation time. Journal of Applied Oral Science, 15(4), 305309.

21. Jain, V., Platt, J. A., Moore, K., Spohr, A. M., \& Borges, G. A. (2013). Color stability, gloss, and surface roughness of indirect composite resins. Journal of oral science, 55(1), 9-15.
22. Attin, T., Manolakis, A., Buchalla, W., \& Hannig, C. (2003). Influence of tea on intrinsic colour of previously bleached enamel. Journal of Oral Rehabilitation, 30(5), 488-494.

23. Keyf, F., \& Yalcin, F. (2005). The weight change of various light-cured restorative materials stored in water. J Contemp Dent Pract, 6(2), 72-79.

24. Knobloch, L. A., Kerby, R. E., McMillen, K., \& Clelland, N. (2000). Solubility and sorption of resin-based luting cements. Operative Dentistry, 25(5), 434-440.

25. Keyf, F., \& Yalcin, F. (2005). The weight change of various light-cured restorative materials stored in water. J Contemp Dent Pract, 6(2), 72-79.

26. Hegde, M. N., \& Biradar, B. (2008). Evaluation of weight change in three different light cured composite restorative materials stored in water: An in vitro study. Journal of conservative dentistry: JCD , 11(3), 108.

27. Sonarkar, S., \& Purba, R. (2015). Bioactive materials in conservative dentistry. Int J Contemp Dent Med Rev, 2015, 1-4.

28. Miyazaki, C. L., Medeiros, I. S., Santana, I. L., Matos, J. D. R., \& Rodrigues Filho, L. E. (2009). Heat treatment of a direct composite resin: influence on flexural strength. Brazilian oral research, 23(3), 241-247.

29. Gupta, G., \& Gupta, T. (2011). Evaluation of the effect of various beverages and food material on the color stability of provisional materials-An in vitro study. Journal of conservative dentistry: $J C D, 14(3), 287$.

30. Malhotra, N., Shenoy, R. P., Acharya, S., Shenoy, R., \& Mayya, S. (2011). Effect of three indigenous food stains on resin- based, microhybrid- , and nanocomposites. Journal of Esthetic and Restorative Dentistry, 23(4), 250-257.

31. Patel, S. B., Gordan, V. V., Barrett, A. A., \& Shen, C. (2004). The effect of surface finishing and storage solutions on the color stability of resinbased composites. The Journal of the American Dental Association, 135(5), 587-594.

32. Alawjali, S. S., \& Lui, J. L. (2013). Effect of onestep polishing system on the color stability of nanocomposites. Journal of dentistry, 41, e53-e61.

33. Lainović, T., Blažić, L., Kukuruzović, D., Vilotić, M., Ivanišević, A., \& Kakaš, D. (2014). Effect of diamond paste finishing on surface topography and roughness of dental nanohybrid composites-AFM analysis. Procedia Eng, 69, 945-51.

34. ABU- BAKR, N. E. A. M. A. T., Han, L., Okamoto, A., \& IWAKU, M. (2000). Color stability of compomer after immersion in various media.Journal of Esthetic and Restorative Dentistry, 12(5), 258-263. 